\title{
Evaluation of the Relationship Between Resting Heart Rate and Endocan, Thrombomodulin Levels in Healthy Adults
}

\section{(1) Sadettin Selçuk Baysal}

Şanlıurfa Mehmet Akif İnan Training and Research Hospital, Clinic of Cardiology, Şanlıurfa, Turkey

\begin{abstract}
Objectives: Resting heart rate (RHR) is a physiological parameter that has been reported to be associated with endothelial dysfunction. Endocan and thrombomodulin are mediators released from endothelium, which are determined to increase in blood with endothelial damage. We aimed to investigate the relationship between RHR and these biomarkers.

Materials and Methods: Sixty-eight healthy volunteers (28 females; mean age: $44.2 \pm 6.3$ years) were included in the study. Subjects divided into two groups according to heart rate quartiles: lower two quartiles as group $1(n=35$, and upper two quartiles as group $2(n=33)$. Endocan and thrombomodulin levels in blood of the individuals were
\end{abstract}

measured.

Results: Clinical features and laboratory findings were similar in both groups ( $>0.05$ for all variables). Mean RHRs were $70.9 \pm 4.9$ in group 1 and $84.8 \pm 4.3$ in group 2 . No statistically significant difference was found in endocan and thrombomodulin levels in both groups ( $p>0.05$ for all variables). No significant correlation was detected between RHR and these molecules.

Conclusion: RHR was not associated with endothelium derived biomarkers endocan and thrombomodulin.

Keywords: Resting heart rate, endothelial dysfunction, biomarker, endocan, thrombomodulin

Address for Correspondence: Sadettin Selçuk Baysal, Şanlıurfa Mehmet Akif İnan Training and Research Hospital, Clinic of Cardiology, Şanlıurfa, Turkey

Phone: +90 5359696274 e-mail: sselcukbaysal@hotmail.com ORCID ID: orcid.org/0000-0003-0125-5024

Received: 11.05.2019 Accepted: 28.05.2019

Cite this article as: Baysal S. Evaluation of the Relationship Between Resting Heart Rate and Endocan, Thrombomodulin Levels in Healthy Adults. EJCM 2019;7(2):89-93.

DOI: $10.32596 /$ ejcm.galenos.2019.00028 


\section{Introduction}

Resting heart rate (RHR) is an indicator of the autonomic nervous system balance and its increase shows that this balance is impaired in favor of sympathetic system. In epidemiological studies, increased heart rate was found to be associated with poor prognosis in cardiovascular diseases (CVD), especially in coronary artery disease (CAD), independent of other known cardiovascular risk factors ${ }^{(1-3)}$. Although the underlying mechanism is not fully understood, it has been reported in experimental and clinical studies that the increase in RHR accused of endothelial dysfunction with increased sympathetic activity and mechanical stress on the vessel wall which led to atherosclerosis ${ }^{(4-7)}$.

A healthy endothelium is essential in the regulation of vascular tone, platelet adhesion, inflammation, fibrinolysis and vascular proliferation. In doing so, the endothelium secretes a variety of mediators, primarily nitric oxide. Thrombomodulin (sTM) and endocan are two of these released from the endothelium and shown to be associated with endothelial dysfunction ${ }^{(8-11)}$.

Based on the studies showing the relationship between RHR and endothelial dysfunction ${ }^{(6,7)}$, in healthy adults we aimed to investigate the relationship between RHR and endocan, sTM which is thought to play a role in endothelial dysfunction.

\section{Materials and Methods}

A total of 68 healthy volunteers whose age were between 18 and 65 years were consecutively enrolled in the study. All individuals were included in the study after a detailed medical evaluation including clinical history, physical examination, routine laboratory panel, electrocardiography (ECG) and echocardiography. Hypertension, diabetes mellitus, CAD, significant valvular heart disease, heart failure (left ventricular ejection fraction $<40 \%$ ), inflammatory diseases (acute or chronic), smoking, use of any medical drugs which have an impact on heart rate and hepatic, thyroid and renal disorders were the exclusion criteria. Twenty-four hours of Holter monitoring with Promedic HECG-12 Holter management system including Ambulatory ECG Systems software running under Microsoft Windows was applied to all cases. All patients were advised to avoid activities that could increase heart rate, such as smoking and drinking coffee during the holter recording. RHR was calculated by the mean of the three lowest heart rates obtained from day time (09:00 a.m.-10:00 p.m.) recordings by two blinded cardiologists. Nighttime heart rate was excluded due to concerns regarding the influence of diurnal variation ${ }^{(12)}$. Subjects were grouped according to quartiles of RHR as per most previous heart rate studies ${ }^{(13)}$. Subjects with lower two quartiles heart rate between $60-78$ beat/ min were included in group 1 and subjects with upper two quartiles heart rate between $79-96$ beat/min were included in group 2. Informed consent was obtained from all participants and the study was approved by Harran University Ethics Committee with project number 74059997.0510.01.04/107.

All biochemical and hematologic values were on the day of sample collection following a fasting period of 12 hours. The Abbott Diagnostics C8000i auto-analyzer (Abbott, Wiesbaden, Germany) was used to determine all biochemical panels. Blood samples were collected into plain tubes and serum was separated after centrifugation at $1,500 \mathrm{~g}$ for 10 minutes and stored at $-80^{\circ} \mathrm{C}$ for analysis of sTM and endocan. Both serum endocan and sTM levels were measured using a sandwich enzyme-linked immunosorbent assay (ELISA) kit with high sensitivity and specificity for detecting human endocan (Cusabio Bioscience Inc, Wuhan, China). The minimum detectable concentrations of endocan and TM were $0.039 \mathrm{ng} / \mathrm{mL}$ and $7.8 \mathrm{pg} / \mathrm{mL}$, respectively. The intra-and inter-assay coefficients of variation were less than $8 \%$ and $10 \%$, respectively, for both biomarkers ${ }^{(8,9)}$.

\section{Statistical Analysis}

SPSS for Windows software (ver. 22.0; SPSS Inc., Chicago, IL, USA) was used for statistical analyses. A Shapiro-Wilks test was applied to assess the normality of the distributions of continuous variables. For comparison, the independent samples t-test or Mann-Whitney U test 
were used where appropriate. The results were presented mean \pm standard deviation or median (minimummaximum). Pearson's correlation analysis was performed for normally distributed variables. $\mathrm{P}$ value $<0.05$ was considered to indicate statistical significance.

\section{Results}

Demographic, clinical and laboratory data of the study sample were given in Table 1. A total of 68 individuals with mean age $44.2 \pm 6.3$ years were enrolled in this study. Group 1 consisted of 35 patients (21 men) with mean age $44.9 \pm 7.1$ years and group 2 consisted of 33 subjects (19 men) with mean age 43.3 \pm 7.7. With respect to age, gender, body mass index (BMI), lipid panel, creatinine, fasting glucose, high-sensitive C-reactive protein (hsCRP) and hemoglobin levels there were not any significant difference between groups. Normally distributed RHR values of the study population are shown in Figure 1. Mean RHR values were $70.9 \pm 4.9$ in group 1 and $84.8 \pm 4.3$ in group 2.

Table 1. Baseline demographic, clinical and laboratory characteristics of the study population

\begin{tabular}{|c|c|c|c|}
\hline & Group $1(n=35)$ & $\begin{array}{l}\text { Group } 2 \\
(n=33)\end{array}$ & $P$ value \\
\hline RHR (beats/min) & $70.9 \pm 4.9$ & $84.8 \pm 4.3$ & $<0.001$ \\
\hline Age, years & $44.9 \pm 7.1$ & $43.3 \pm 7.7$ & 0.24 \\
\hline $\mathrm{SBP}(\mathrm{mmHg})$ & $121 \pm 7$ & $122 \pm 6$ & 0.67 \\
\hline $\mathrm{DBP}(\mathrm{mmHg})$ & $78 \pm 5$ & $79 \pm 4$ & 0.76 \\
\hline Female, n (\%) & $14(40)$ & $14(42)$ & 0.79 \\
\hline $\mathrm{BMI}, \mathrm{kg} / \mathrm{m}^{2}$ & $25.9 \pm 2.8$ & $25.3 \pm 1.7$ & 0.56 \\
\hline $\begin{array}{l}\text { Total cholesterol, } \\
\mathrm{mg} / \mathrm{dL}\end{array}$ & $185(133-270)$ & $190(84-256)$ & 0.52 \\
\hline LDL, mg/dL & $104 \pm 29$ & $109 \pm 21$ & 0.66 \\
\hline $\mathrm{HDL}, \mathrm{mg} / \mathrm{dL}$ & $35.4 \pm 6.2$ & $34.7 \pm 7.3$ & 0.75 \\
\hline Triglyceride,mg/dL & $195(85-317)$ & $181(75-303)$ & 0.69 \\
\hline $\begin{array}{l}\text { Fasting glucose, mg/ } \\
\mathrm{dL}\end{array}$ & $87(72-105)$ & $89(79-103)$ & 0.84 \\
\hline Creatinine, $\mathrm{mg} / \mathrm{dL}$ & $0.77 \pm 0.12$ & $0.80 \pm 0.17$ & 0.35 \\
\hline Hemoglobin, g/dL & $15.5(13.1-16.8)$ & $15.2(13.4-17)$ & 0.74 \\
\hline hsCRP, mg/dL & $0.46 \pm 0.21$ & $0.44 \pm 0.23$ & 0.56 \\
\hline \multicolumn{4}{|c|}{$\begin{array}{l}\text { RHR: Resting heart rate, SBP: Systolic blood pressure, DBP: Diastolic } \\
\text { blood pressure BMI: Body mass index, HDL: High-density lipoprotein, } \\
\text { hsCRP: high sensitive C-reactive protein, LDL: Low-density lipoprotein, } n \text { : } \\
\text { Number of the patients } \\
\text { Values are expressed as mean } \pm \text { standard deviation }\end{array}$} \\
\hline
\end{tabular}

There was not any significant difference in endocan and sTM concentration between groups as shown in Figure 2 ( $\mathrm{p}=0.23$ and $\mathrm{p}=0.81$ respectively). In correlation analysis, no significant association was found between RHR and endocan, sTM (Table 2).

\section{Discussion}

RHR is a simple non-invasive physiological parameter of autonomic dysfunction which was reported to be a strong predictor of adverse cardiovascular events and allcause mortality both in healthy individuals and population with CVD in epidemiologic studies ${ }^{(1-3,14)}$. In some studies, although heart rate was suggested to be associated with CVD independent of other known risk factors, others claimed that this relationship was dependent to confounding risk factors ${ }^{(3,15,16)}$. Moreover, RHR has been found to be associated with sudden cardiac death and cardiovascular risk factors such as diabetes, hypertension, dyslipidemia and obesity ${ }^{(17-19)}$.

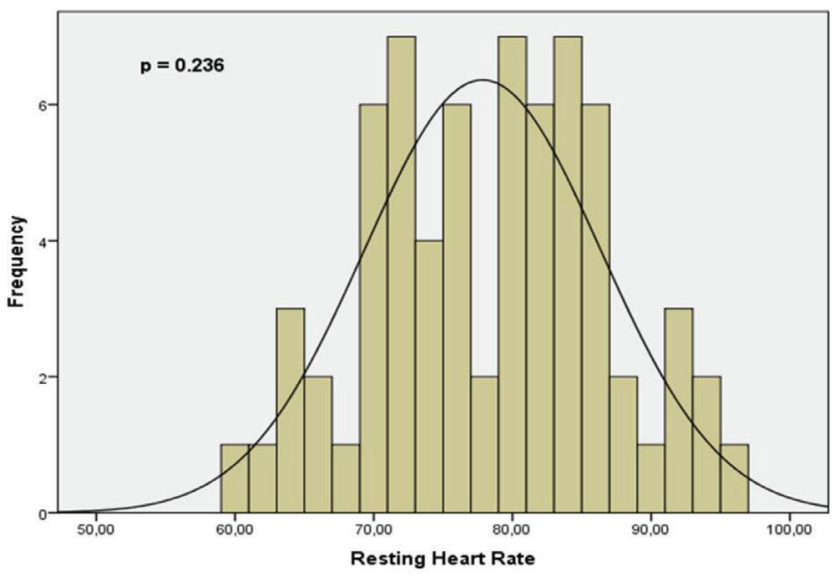

Figure 1. Histogram of the resting heart rate distribution of the study population

Table 2. Correlation between resting heart rate and other parameters

\begin{tabular}{l|l|l|} 
& Coefficient $^{*}$ & $\mathbf{p}$ \\
\hline Age & -0.245 & 0.33 \\
\hline BMI & 0.354 & 0.24 \\
\hline Thrombomodulin & 0.261 & 0.19 \\
\hline Endocan & 0.378 & 0.21 \\
\hline hsCRP & -0.215 & 0.42
\end{tabular}

BMI: Body mass index, hsCRP: High sensitive C-reactive protein ${ }^{*}$ From Pearson's correlation analysis 
Previous studies have presented strong evidence proving the association between increased RHR and many stages of atherosclerosis, such as endothelial dysfunction, CAD severity, and even plaque rupture ${ }^{(5,6)}$. An increase in RHR increases the frequency and strength of the mechanical load applied to the arterial wall. Relatively shortening of the duration of diastole as a result of the increase in heart rate causes increase in the time spent in systole which prolong the exposure of arterial endothelium to the systolic low and oscillatory shear
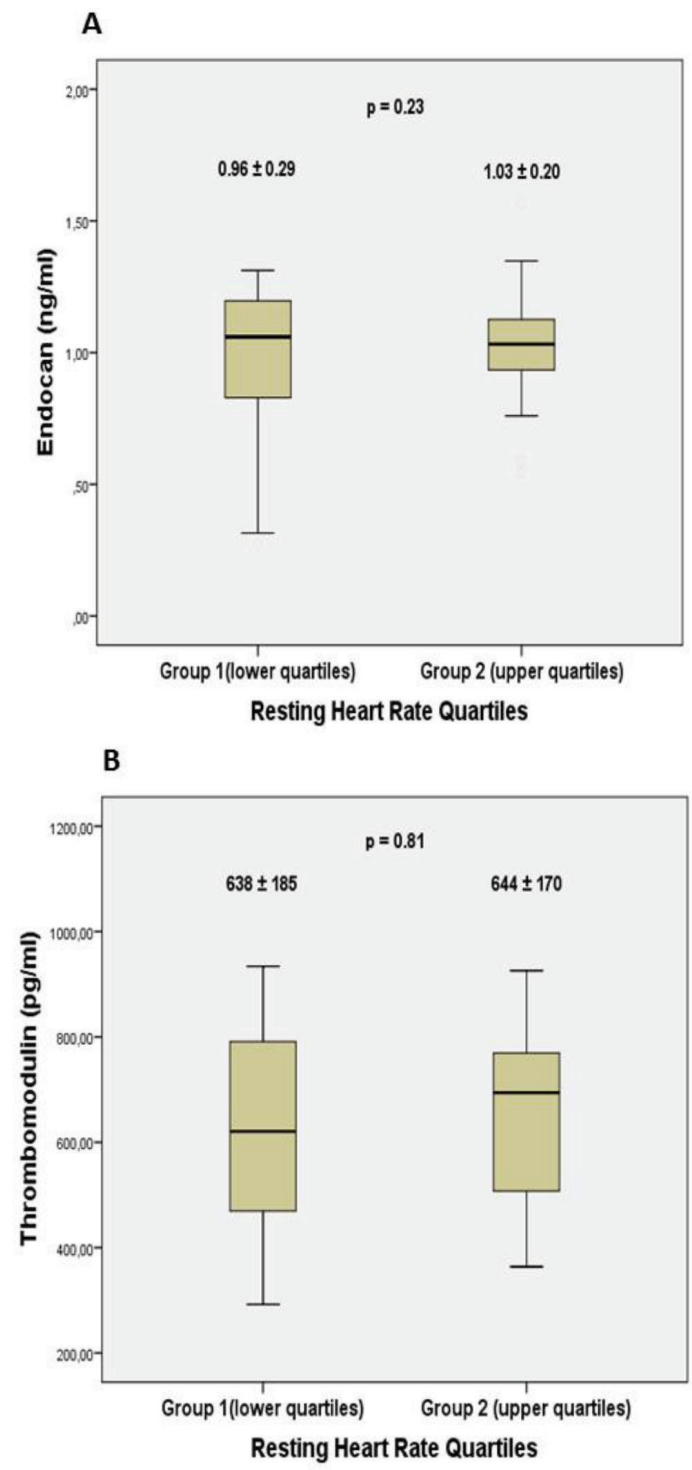

Figure 2. (A) Endocan, (B) thrombomodulin levels of the study population grouped by heart rate quartiles stress. Furthermore, increase in frequency of periodically change in arterial geometry due to high heart rate promotes the power of tensile and shear stress on the vascular wall. All these changes induce structural changes in vascular endothelium which promotes vascular stiffening and then atherosclerosis $^{(5)}$.

In a study conducted in a multiethnic population with 6484 participants, RHR was associated with increased arterial stiffness, which is an indicator of endothelial dysfunction ${ }^{(20)}$. Moreover, both in animal studies and in human studies, the beneficial effects of decreased heart rate on endothelial function have been demonstrated ${ }^{(4,6,7)}$. Endocan and TM are two molecules released from endothelium that have been shown to be associated with endothelial dysfunction in previous studies ${ }^{(8-11)}$. In our study, we tried to evaluate the relationship between RHR and endothelial function by investigating whether there is a relationship between these endothelium derived molecule levels and RHR in healthy participants. Our study groups were homogeneous according to their demographic, clinical and laboratory characteristics. In our work, we did not detect any difference in both sTM and endocan levels in patients grouped due to their heart rates (Figure 2). Unlike previous studies mentioned, we did not find any relationship between RHR and these biomarkers which are thought to have role in endothelial dysfunction. We also did not detect any relationship between RHR and age, gender and BMI. Although previous studies have shown a positive correlation between the hsCRP concentration ${ }^{(13,21)}$. which is an indicator of inflammation, and RHR, we did not find any relationship in our study.

Observational design and relatively small sample may be the reasons of our study's inability to detect significant correlations. Single time measurement of biomarkers could not clearly reflect the long-term state of subjects. We did not also measure nitric oxide level, which is considered to be the primary biomarker in demonstrating endothelial functions. Lack of evaluating heart rate variability, psychiatric disorders and social background 
variables such as economic and education status are the other limitations of our study.

Our study results presented that RHR was not associated neither with endothelium derived biomarkers STM and endocan nor with age, gender and BMI. Further large prospective studies with large sample size are required to its clinical utility.

\section{Acknowledgements}

I thank Harran University Biochemistry Department and Dr. Esra Nur Uçkan Yetkin.

\section{Ethics}

Ethics Committee Approval: This study was approved by Harran University Ethics Committee with project number 74059997.0510.01.04/107.

Informed Consent: Informed consent was obtained from all participants.

\section{Peer-review: Externally peer-reviewed.}

Financial Disclosure: All support for this study came from institutional and departmental resources.

\section{References}

1. Woodward M, Webster R, Murakami Y, et al. The association between resting heart rate, cardiovascular disease and mortality: evidence from 112,680 men and women in 12 cohorts. European journal of preventive cardiology. 2014;21:719-26.

2. Tverdal A, Hjellvik V, Selmer R. Heart rate and mortality from cardiovascular causes: a 12 year follow-up study of 379843 men and women aged 40-45 years. European heart journal. 2008;29:2772-81.

3. Jensen MT, Suadicani P, Hein HO, et al. Elevated resting heart rate, physical fitness and all-cause mortality: a 16-year follow-up in the Copenhagen Male Study. Heart. 2013;99:882-7.

4. Thorin E, Thorin-Trescases N. Vascular endothelial ageing, heartbeat after heartbeat. Cardiovascular research. 2009;84:24-32

5. Giannoglou GD, Chatzizisis YS, Zamboulis C, et al. Elevated heart rate and atherosclerosis: an overview of the pathogenetic mechanisms. International journal of cardiology. 2008;126:302-12.

6. Custodis F, Baumhäkel M, Schlimmer N, et al. Heart rate reduction by ivabradine reduces oxidative stress, improves endothelial function, and prevents atherosclerosis in apolipoprotein E-deficient mice. Circulation. 2008; 117:2377-87.

7. Fox K, Ford I, Steg PG, et al. Heart rate as a prognostic risk factor in patients with coronary artery disease and left-ventricular systolic dysfunction
(BEAUTIFUL): a subgroup analysis of a randomised controlled trial. The Lancet. 2008;372:817-21.

8. Baysal SS, Koc S, Kaya BC, et al. Relationship between the endothelium biomarkers endocan and thrombomodulin and slow coronary flow. Biomedical Research. 2018;29:1345-50.

9. Baysal SS, Koç Ş, Güneş A, et al. Endothelium biomarkers endocan and thrombomodulin levels in isolated coronary artery ectasia. European review for medical and pharmacological sciences. 2018;22:4677-82.

10. Balta S, Mikhailidis DP, Demirkol S, et al. Endocan: a novel inflammatory indicator in cardiovascular disease? Atherosclerosis. 2015;243:339-43.

11. Martin FA, Murphy RP, Cummins PM. Thrombomodulin and the vascular endothelium: insights into functional, regulatory, and therapeutic aspects. American Journal of Physiology-Heart and Circulatory Physiology. 2013;304:H1585-H97.

12. Carlson N, Dixen U, Marott JL, et al. Predictive value of casual ECG-based resting heart rate compared with resting heart rate obtained from Holter recording. Scandinavian journal of clinical and laboratory investigation. 2014;74:163-9.

13. Inoue $\mathrm{T}$, Iseki $\mathrm{K}$, Iseki $\mathrm{C}$, et al. Elevated resting heart rate is associated with white blood cell count in middle-aged and elderly individuals without apparent cardiovascular disease. Angiology. 2012;63:541-6.

14. Jensen MT, Marott JL, Allin KH, et al. Resting heart rate is associated with cardiovascular and all-cause mortality after adjusting for inflammatory markers: the Copenhagen City Heart Study. European journal of preventive cardiology. 2012;19:102-8.

15. Simula S, Vanninen E, Lehto $\mathrm{S}$, et al. Heart rate variability associates with asymptomatic coronary atherosclerosis. Clinical Autonomic Research. 2014;24:31-7.

16. Johansen CD, Olsen RH, Pedersen LR, et al. Resting, night-time, and 24 $\mathrm{h}$ heart rate as markers of cardiovascular risk in middle-aged and elderly men and women with no apparent heart disease. European heart journal. 2013;34:1732-9

17. Jouven X, Zureik M, Desnos M, et al. Resting heart rate as a predictive risk factor for sudden death in middle-aged men. Cardiovascular research. 2001;50:373-8.

18. Franklin BA, Chaddha A. Resting Heart Rate and Blood Pressure as Indices of Cardiovascular and Mortality Risk: Is lower invariably better? Journal of cardiopulmonary rehabilitation and prevention. 2018;38:353-7.

19. Lee DH, de Rezende LFM, Hu FB, et al. Resting heart rate and risk of type 2 diabetes: a prospective cohort study and meta-analysis. Diabetes/ metabolism research and reviews. 2018:e3095.

20. Whelton SP, Blankstein R, Al-Mallah MH, et al. Association of resting heart rate with carotid and aortic arterial stiffness: Multi-Ethnic Study of Atherosclerosis (MESA). Hypertension. 2013;62.

21. Whelton SP, Narla V, Blaha MJ, et al. Association between resting heart rate and inflammatory biomarkers (high-sensitivity C-reactive protein, interleukin-6, and fibrinogen)(from the Multi-Ethnic Study of Atherosclerosis). The American journal of cardiology. 2014;113:644-9. 